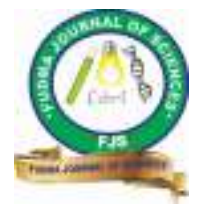

FUDMA Journal of Sciences (FJS)

ISSN online: $2616-1370$

ISSN print: 2645 - 2944

Vol. 4 No. 3, September, 2020, pp $48-51$

DOI: https://doi.org/10.33003/fjs-2020-0403-255

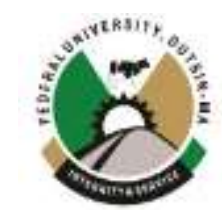

\title{
COMPARATIVE ANALYSIS OF THREE PLANE GEOMETRIC GEOID SURFACES FOR ORTHOMETRIC HEIGHT
} MODELLING IN KAMPALA, UGANDA

\author{
${ }^{* 1}$ Kyamulesire, B., ${ }^{2}$ Oluyori, P. D. and ${ }^{3}$ Eteje, S. O. \\ ${ }^{1}$ Associated Mapping Professionals, P. O. Box 5309, Jinja, Uganda \\ ${ }^{2}$ P. D. Horvent Surveys Ltd, Abuja Nigeria \\ ${ }^{3}$ Eteje Surveys and Associates, Benin City, Edo State, Nigeria \\ *Corresponding Author Email: bbkyamulesire@gmail.com
}

\begin{abstract}
The conversion of theoretical, as well as geometric heights to practical heights requires the application of geoidal undulations from a geoid model. The various global geopotential models that are readily available for application in any part of the world do not best-fit regions, as well as countries. As a result, there is a need to determine the local geoid models of local areas, regions and countries. This study determines the local geoid model of Kampala in Uganda for orthometric heights computation by comparing three plane geometric geoid surfaces. A total of 19 points were used in the study. The least squares adjustment technique was applied to compute the models' parameters. Microsoft Excel programs were developed for the application of the models in the study area. The Root Mean Square Index was applied to compute the accuracy of the models. The three geometric geoid models were compared using their accuracy to determine which of them is most suitable for application in the study area. The comparison results show that the three models can be applied in the study area with more reliability, with greater confidence in model 2.
\end{abstract}

Keywords: Local Geoid, Modelling, Geometric Surface, Ellipsoidal Height, Orthometric Heights

\section{INTRODUCTION}

Research and Development of a system of Global Navigation Satellite System (GNSS) positioning have made a method of surveying faster, easier and more accurate than before in the application of both scientific and applied geodesy and especially for geoid modelling when gravity data is unavailable. The geoid according to Heiskanen and Moritz (1967) is the "mathematical figure of the earth". It is the surface which coincides with the mean sea level assuming that the sea was free to flow under the land in small frictionless channels. Ubajekwe (2011) explained further that the mean sea level is not quite an equipotential surface owing to nongravitational forces (such as ocean currents, winds and barometric pressure variation). In geodetic surveying, the computation of the geodetic coordinates of points is commonly performed on a reference ellipsoid closely approximating the size and shape of the earth in the area of the survey. The actual measurements made on the surface of the earth with certain instruments are however referred to the geoid (Oduyebo et al., 2019). The geoid may be obtained by modelling from among others to serve as a vertical reference, as well as a datum for height determination. A global geoid is designed as global bestfit for the whole world with each country adopting her own local or regional version to fit her own mapping needs and purposes, as well as serve as a datum in engineering specifications.

The geoid surface being a continuous equipotential surface is used in defining the heights vertical reference in place of unreliable mean sea level. Local geoid modelling of areas/regions has become crucial as the GNSS ellipsoidal heights are not practical heights used in engineering constructions. The GNSS ellipsoidal heights are theoretical heights obtained by computation on a specified ellipsoid. To apply the said heights in engineering constructions, a conversion is necessary. To do this, a geoid model is required to obtain the occupied points/controls respective geoid heights. Having obtained the geoid heights of the points from the geoid model, the orthometric heights of the respective points are obtained using the relation (Oluyori, at al. 2018):

$$
H=h-N
$$

Where,

$$
\begin{aligned}
& \mathrm{H}=\text { Orthometric height } \\
& \mathrm{h}=\text { Ellipsoidal height } \\
& \mathrm{N}=\text { Geoid height }
\end{aligned}
$$

Different studies have determined the local geoid models of various areas with different accuracy achieved. Oduyebo et al. (2019) determined the local geoid model of Benin City by comparing three gravimetric-geometric geoid models of the study area with an accuracy of $0.6746 \mathrm{~m}$. Oluyori et al. (2018) also determined the local geoid model of the Federal Capital Territory, Abuja, where the accuracy of $0.419 \mathrm{~m}$, was obtained by comparing GNSS/Levelling and EGM 2008 geoidal undulations.

Although, Uganda gravimetric geoid model of 2014 (UGG2014) had been experimented successfully by the KTH method for orthometric height determination using the GNSS equipment (Ssengendo et al., 2015a). The experiment was carried out using a global geopotential model (EIGEN-6C4). Global geopotential models are determined for application in 
any part of the world. They best fit the entire globe but not local areas, regions or countries. Their application at local areas, regions and countries, yield less accurate results. Consequently, there is a need to determine local geoid models of areas, regions and countries. This study comparatively analyses three geometric geoid surfaces using observed GNSS ellipsoidal heights and existing orthometric heights to determine the most suitable geoid surface for application in the Kampala area.

The geometric method of local geoid modelling is applied to small areas. A study has stated that a small area is the one that is less than $200 \mathrm{~km}^{2}$ in size (Schofield, 2007). In surface fitting methods, models adopted depend on the size and nature of the variation of the heights of the points used as opined Oluyori (2019). As such, Romans (2007) suggested that for small areas, models with four parameters or lower, be adopted for better accuracy. Kampala has an area of $196 \mathrm{~km}^{2}$ which by Romans (2007) was classified as a small area in this study.

Objectives of the study are: to determine ellipsoidal heights of controls from dual-frequency DGPS observations; to obtain the geoidal heights $(\mathrm{N})$ of the controls by finding the differences between the GNSS ellipsoidal heights and the existing orthometric heights; to develop Microsoft Excel programs to compute the models' parameters, geoid heights, orthometric heights and the accuracy, and to compare the computed models' accuracy to obtain the most suitable model for application in the study area.

\section{The Study Area}

Kampala is the capital city of Uganda and occupies a series of hills at an average elevation of $1,190 \mathrm{~m}$ and is located north of Lake Victoria. It has an area of $196 \mathrm{~km}^{2}$. The City today has grown into a Commercial, Educational, Cultural and Administrative Centre of Uganda with an approximate population of 2.5 million people. Considering that the population was 330,700 in $1969,1,208,544$ in 2002, and $1,811,794$ in 2010 , this signals rapid urbanization in the country (Oonyu and Esaete 2012). Quite a lot of survey and mapping, as well as engineering activities, must be expected. The study area falls within the UTM zone $36 \mathrm{~N}$ rectangular coordinate system.

\section{Topography}

Kampala is made up of Central, Kawempe, Makindye, Nakawa and Lubaga divisions and it sits on hills including; Kasubi Hill, Mengo Hill, Kibuli Hill, Namirembe Hill, Rubaga Hill, Nsambya and old Kampala Hill. Figure 1 shows the location of Kampala in Uganda and its five divisions as located within its boundaries.

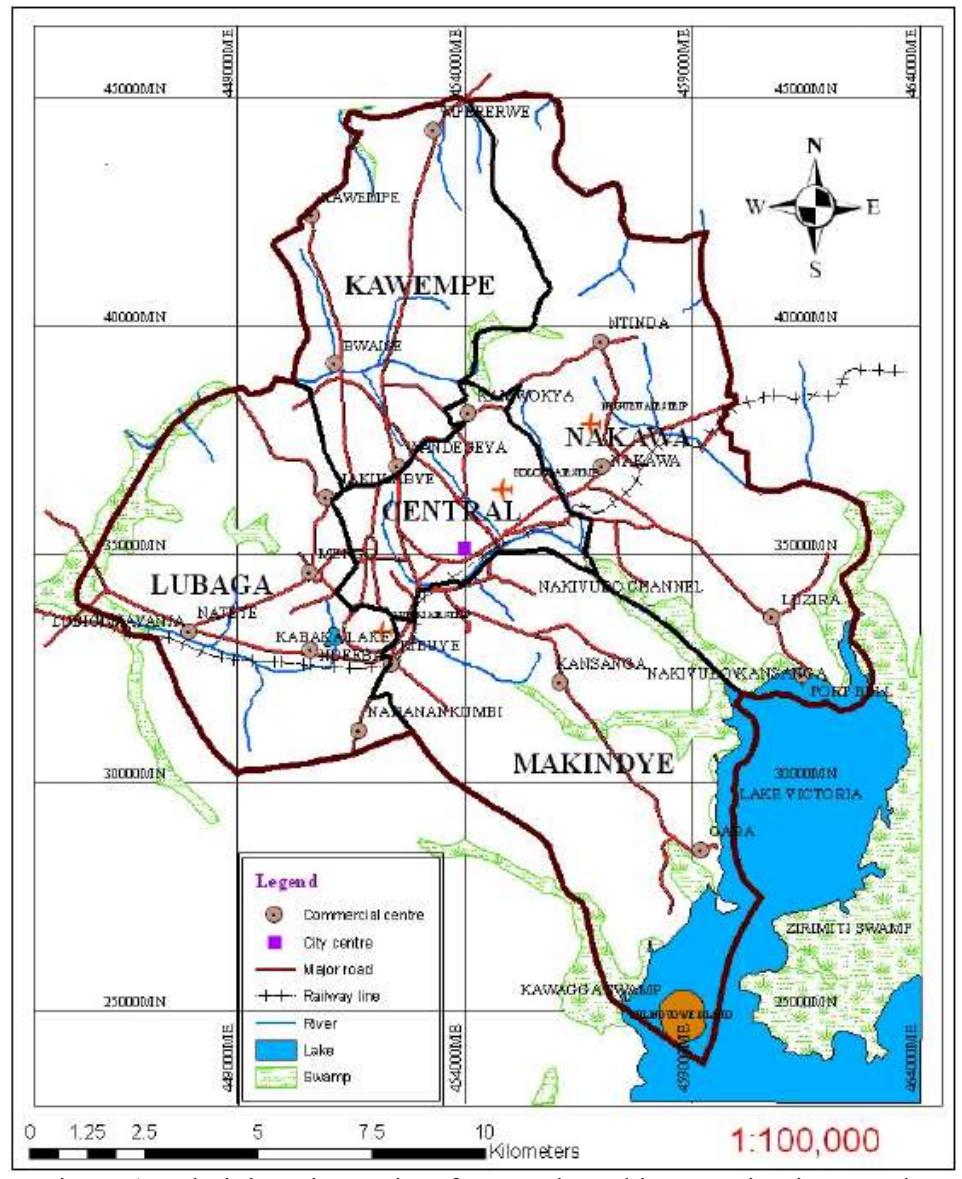

Figure 1: Administrative Units of Kampala and its Location in Uganda Source: Irumba (2015) 
Plane Geometric Geoid Surfaces

Plane geometric geoid surfaces are geoid models with the highest degree as 1 . They are used to model the local geoid of small areas. The plane geometric geoid surfaces given by Abdallah (2010) as model 1, model 2 and model 3 are respectively

$$
\begin{aligned}
& N_{i}=a_{0}-a_{1} x_{i}+a_{2} y_{i} \\
& N_{i}=a_{0}+a_{1} x_{i}+a_{2} y_{i}+a_{3} x_{i} y_{i} \\
& N_{i}=a_{0}+a_{1} x_{i}+a_{2} y_{i}+a_{3} \Delta h
\end{aligned}
$$

Where,

$$
\begin{aligned}
& N_{i}=\text { Geoid height } \\
& x_{i}=\text { Northing of the observed point } \\
& y_{i}=\text { Easting of the observed point } \\
& \Delta h=\text { Difference between the average ellipsoidal heights of the observed points and individual point } \\
& a_{0}, a_{1}, a_{2}, a_{3}=\text { Model parameters }
\end{aligned}
$$

The application of equations (2), (3) and (4) in local geometric geoid modelling, requires the use of least squares technique to obtain the models' parameters. And it involves the writing of observation equations. Here, the number of observation equations to be written must equal the number of the observed points. The least squares models and the procedures used for the computation of the geometric geoid model parameters are detailed in Eteje and Oduyebo (2018) and Eteje, et al., (2018).

\section{Root Mean Square Error Computation (RMSE)}

The Root Mean Square Error (RMSE) is an indicator of accuracy. It is used for the computation of the accuracy of local geometric geoid models. Its application for accuracy computation in geoid modelling involves the comparison of the computed geoid heights obtained from the differences between the ellipsoidal and the orthometric heights and the model geoid heights of points. Also, the RMSE of the geometric geoid model can be obtained using the known and the model orthometric heights. The RMSE index used for accuracy computation as given by Eteje and Oduyebo (2018) is

$$
R M S E= \pm \sqrt{\frac{V^{T} V}{n}}
$$

Where,

$$
\begin{aligned}
& V=(N / H)_{K N O W N}-(N / H)_{M O D E L} \\
& (N / H)_{K N O W N}=\text { Point known geoid/orthometric height } \\
& (N / H)_{M O D E L}=\text { Point model geoid/orthometric height } \\
& n=\text { Number of points }
\end{aligned}
$$

\section{The Gravity Field Model EIGEN-6C4}

According to Kostelecký et al. (2015), EIGEN-6C4 (European Improved Gravity model of the Earth by New techniques) is a static global combined gravity field model up to degree and order 2190. It has been elaborated jointly by GFZ Potsdam and GRGS Toulouse and contains the following satellite and ground data:

1. LAGEOS-1/2 (deg. 2 - 30): Satellite Laser Ranging data $1985-2010$

2. GRACE, GNSS-SST and K-band range-rate data, processing according to RL03 GRGS (deg. 2 - 130): ten years $2003-2012$

3. GOCE, Satellite Gravity Gradiometry (SGG) data, processed by the direct approach including the gravity gradient components Txx, Tyy, Tzz and Txz out of the following time spans 837 days out of the nominal mission period 20091101 - 20120801, 422 days out of the lower orbit phase between 20120801 - 20131020.

4. Terrestrial data (max degree 370 ): DTU12 ocean geoid data and an EGM2008 geoid height grid for the continents. The combination of these different satellites and surface data sets has been done by a band-limited combination of normal equations (to maximum degree/order 370), which are generated from observation equations for the spherical harmonic coefficients (Shako et al., 2013, Kostelecký et al., 2015). The resulted solution to degree/order 370 has been extended to degree/order 2190 by a block diagonal solution using the DTU10 global gravity anomaly data grid.

The EIGEN6C4 has been evaluated and adopted for geodetic computation, as well as geoidal heights and orthometric heights determination in Uganda.

\section{METHODOLOGY}

\section{Data Acquisition}

A total of 19 points, were used in the study, 12 points for the modelling of the geometric geoid of the study area, 4 points (U2004 to U2007) for validation using the existing global geoid model (EIGEN6C4) (MLHUD, 2019) (See Figure 2) and 3 points (71Y121, 71Y126 and 71Y147) also for validation 
using orthometric heights from spirit levelling. Points U2004 to U2007 are respectively located at Road reserve, Kawali Lweza; UNRA Road reserve, Kinaawa; Island of Kira road to Bukoto/Kamwokya, Bukoto and Makerere university business school, Nakawa. The points were observed using Trimble R7 receivers to obtain their coordinates and ellipsoidal heights. 4 of 19 of the existing/known orthometric heights of the points were obtained from the Ministry of Land, Housing and Urban
Development (MLHUD) and 15 of 19 were obtained by a private firm SIG in 1993. The orthometric heights were also obtained from the MLHUD. They were computed using the ellipsoidal heights from GNSS observation carried out with Leica 1200 GPS receivers and accessories and the geoid heights obtained from a global geoid model (EIGEN6C4) adopted for geodetic computation in Uganda.
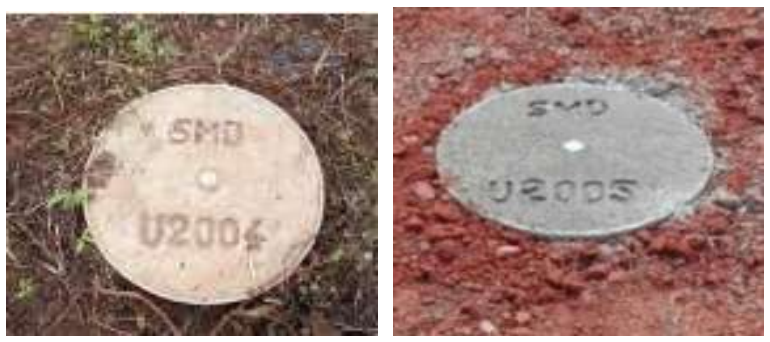

Figure 2: Gravimetric Orthometric Heights Test Points

Source: Ministry of Land, Housing and Urban Development (MLHUD) (2019)

\section{Data Processing}

The GNSS observations were processed in the UTM zone $36 \mathrm{~N}$ on the GRS80 ellipsoid using Bernese (Version 5.0) to obtain the northing, easting and ellipsoidal heights of the occupied controls. The geoid heights of the 12 points used for the local geometric geoid modelling, were computed by finding the differences between the ellipsoidal heights from GNSS observation and the known orthometric heights of the points. Also, the geoid heights of the 3 points used for validation, were computed using the ellipsoidal heights from the GNSS

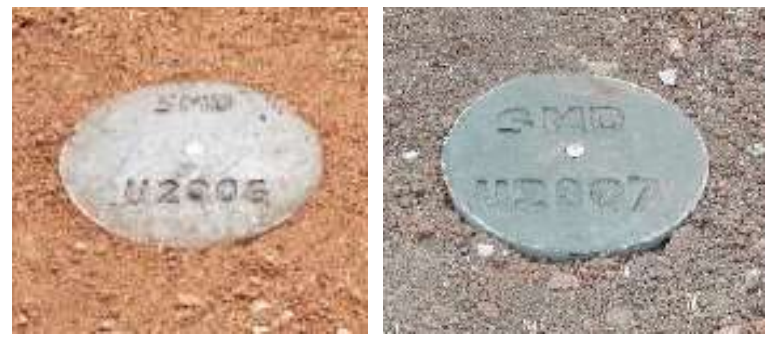

observation and the orthometric heights from the spirit levelling. The geoid heights of the points were computed using equation (1). Those of the 4 validation points, were obtained from EIGEN6C4 using the coordinates of the points. The existing/known orthometric heights were also computed using equation (1). The levelling data of the 3 validation points, were reduced using the height of the instrument/collimation method. Table 1 shows the coordinates, ellipsoidal heights and the known orthometric heights of the 12 points used for the geometric geoid modelling.

Table 1: Coordinates, Ellipsoidal Heights, Geoid Heights and Known Orthometric Heights of the 12 Points

\begin{tabular}{lccccc}
\hline \multicolumn{7}{c}{ Geometric Geoid Modelling Points } \\
\hline STATION & $\begin{array}{c}\text { EASTING } \\
\mathbf{( x )}(\mathbf{m})\end{array}$ & $\begin{array}{c}\text { NORTHING } \\
\mathbf{( y )}(\mathbf{m})\end{array}$ & $\begin{array}{c}\text { ELLIPSOIDAL } \\
\text { HEIGHT, } \mathbf{~ ( m )}\end{array}$ & $\begin{array}{c}\text { Known } \\
\text { ORTHOMETRIC } \\
\text { HEIGHT, H (m) }\end{array}$ & $\begin{array}{c}\text { GEOID HEIGHT, } \\
\text { N (m) }\end{array}$ \\
\hline $\mathbf{7 1 Y 6 5}$ & 449421.520 & 39563.190 & 1209.921 & 1222.122 & -12.215 \\
$\mathbf{7 1 Y 8 0}$ & 451601.150 & 37537.100 & 1253.079 & 1265.410 & -12.334 \\
$\mathbf{7 1 Y 9 7}$ & 451574.520 & 37388.890 & 1255.641 & 1267.942 & -12.337 \\
$\mathbf{7 1 Y 1 2 5}$ & 454888.680 & 34774.920 & 1137.505 & 1150.081 & -12.460 \\
$\mathbf{7 1 Y 1 4 1}$ & 457725.480 & 30265.860 & 1176.309 & 1188.934 & -12.576 \\
$\mathbf{7 1 Y 1 4 3}$ & 457490.680 & 26773.960 & 1152.722 & 1165.290 & -12.639 \\
$\mathbf{7 1 Y 1 4 9}$ & 458258.050 & 35349.840 & 1151.609 & 1164.099 & -12.531 \\
$\mathbf{7 1 Y 1 5 1}$ & 458861.180 & 39178.510 & 1237.155 & 1249.643 & -12.491 \\
$\mathbf{7 1 Y 1 5 2}$ & 458281.140 & 40110.200 & 1211.352 & 1223.836 & -12.443 \\
$\mathbf{7 1 Y 1 5 3}$ & 458393.460 & 42176.260 & 1193.261 & 1205.659 & -12.403 \\
$\mathbf{7 1 Y 1 5 4}$ & 457752.180 & 44442.970 & 1174.250 & 1186.604 & -12.365 \\
$\mathbf{7 1 Y 1 5 5}$ & 459346.620 & 44414.620 & 1171.592 & 1183.980 & -12.410 \\
\hline
\end{tabular}

The computed geoid heights and the positions of the points were applied in equations (2) and (3) to obtain the model parameters of Models 1 and 2. While the parameters of model 3, were computed with the geoid heights, positions and the ellipsoidal heights of the points using equation (4). The model parameters of the three geometric geoid surfaces were computed using the least squares technique, as well as detailed in Eteje and Oduyebo (2018) and Eteje, et al., (2018). Table 2 shows the computed models' parameters. 
Table 2: Computed Models 1, 2 and 3 Parameters

\begin{tabular}{cccccc}
\hline \multicolumn{2}{c}{ Model 1 Parameters } & \multicolumn{2}{c}{ Model 2 Parameters } & \multicolumn{2}{c}{ Model 3 Parameters } \\
\hline $\mathbf{a}_{0}$ & -1.6214917973 & $\mathrm{a}_{0}$ & -72.6223551631 & $\mathrm{a}_{0}$ & -0.8538128360 \\
$\mathbf{a}_{1}$ & -0.0000250195 & $\mathrm{a}_{1}$ & 0.0001301207 & $\mathrm{a}_{1}$ & -0.0000265750 \\
$\mathbf{a}_{2}$ & 0.0000159308 & $\mathrm{a}_{2}$ & 0.0018495211 & $\mathrm{a}_{2}$ & 0.0000150071 \\
& & $\mathrm{a}_{3}$ & -0.0000000040 & $\mathrm{a}_{3}$ & -0.0007055588 \\
\hline
\end{tabular}

The computed parameters and the coordinates of the points were used to develop Microsoft Excel programs using equations (2) and (3) (model 1 and 2 respectively). A Microsoft Excel program was also developed using the computed parameters, coordinates and the ellipsoidal heights of the points with equation (4). The Root Mean Square Errors (RMSEs), as well as the accuracy of the three geometric geoid models, were computed using equation (5). All the computations were done using the developed Microsoft Excel programs. The contour maps of the three models and the known orthometric heights of the points were plotted with Surfer 11 software using the Kriging interpolation method.

\section{RESULTS AND DISCUSSION}

Table 3 presents the three geometric geoid models' orthometric heights and the known orthometric heights of the points. The models' orthometric heights, were obtained by finding the differences between the ellipsoidal and the models' geoid height. They were computed to show the minimum and the maximum orthometric heights of the three geometric geoid models. It can be seen in Table 3 that the minimum and the maximum orthometric heights of the three geometric geoid models, Model 1, Model 2 and Model 3 are respectively $1149.954 \mathrm{~m}$ and $1267.965 \mathrm{~m}, 1149.987 \mathrm{~m}$ and $1267.987 \mathrm{~m}$, and $1149.965 \mathrm{~m}$ and $1267.978 \mathrm{~m}$. It implies that orthometric heights can be respectively obtained using the three models (Models 1, 2 and 3) within the ranges of $1149.954 \mathrm{~m}$ to $1267.965 \mathrm{~m}$, $1149.987 \mathrm{~m}$ to $1267.987 \mathrm{~m}$, and $1149.965 \mathrm{~m} \mathrm{t} 1267.978 \mathrm{~m}$ in the study area.

Table 3: Models 1, 2, 3 and Known Orthometric Heights

\begin{tabular}{ccccc}
\hline STATION & $\begin{array}{c}\text { Model 1 } \\
\text { Orthometric } \\
\text { Height (m) }\end{array}$ & $\begin{array}{c}\text { Model 2 } \\
\text { Orthometric } \\
\text { Height (m) }\end{array}$ & $\begin{array}{c}\text { Model 3 } \\
\text { Orthometric } \\
\text { Height (m) }\end{array}$ & $\begin{array}{c}\text { Known } \\
\text { Orthometric } \\
\text { Height (m) }\end{array}$ \\
\hline $\mathbf{7 1 Y 6 5}$ & 1222.157 & 1222.117 & 1222.136 & 1222.122 \\
$\mathbf{7 1 Y 8 0}$ & 1265.401 & 1265.419 & 1265.413 & 1265.410 \\
$\mathbf{7 1 Y 9 7}$ & 1267.965 & 1267.987 & 1267.978 & 1267.942 \\
$\mathbf{7 1 Y 1 2 5}$ & 1149.954 & 1149.987 & 1149.965 & 1150.081 \\
$\mathbf{7 1 Y 1 4 1}$ & 1188.900 & 1188.889 & 1188.885 & 1188.934 \\
$\mathbf{7 1 Y 1 4 3}$ & 1165.363 & 1165.363 & 1165.361 & 1165.290 \\
$\mathbf{7 1 Y 1 4 9}$ & 1164.133 & 1164.114 & 1164.140 & 1164.099 \\
$\mathbf{7 1 Y 1 5 1}$ & 1249.633 & 1249.624 & 1249.646 & 1249.643 \\
$\mathbf{7 1 Y 1 5 2}$ & 1223.800 & 1223.792 & 1223.795 & 1223.836 \\
$\mathbf{7 1 Y 1 5 3}$ & 1205.679 & 1205.677 & 1205.664 & 1205.659 \\
$\mathbf{7 1 Y 1 5 4}$ & 1186.616 & 1186.605 & 1186.615 & 1186.604 \\
$\mathbf{7 1 Y 1 5 5}$ & 1183.999 & 1184.024 & 1184.002 & 1183.980 \\
\hline
\end{tabular}

Figures 3 to 6 present the contour plots of Models 1, 2, 3 and the known orthometric heights of the points. They were plotted to present graphically, the shapes, as well as the agreements of the three geometric geoid models' orthometric heights with the known orthometric heights. It can be seen in Figures 3 to 6 that the shapes of the three geometric geoid models of the study area are identical with that of the known orthometric heights. It shows the agreement of the three geometric geoid models' orthometric heights with the known orthometric heights of the study area. 

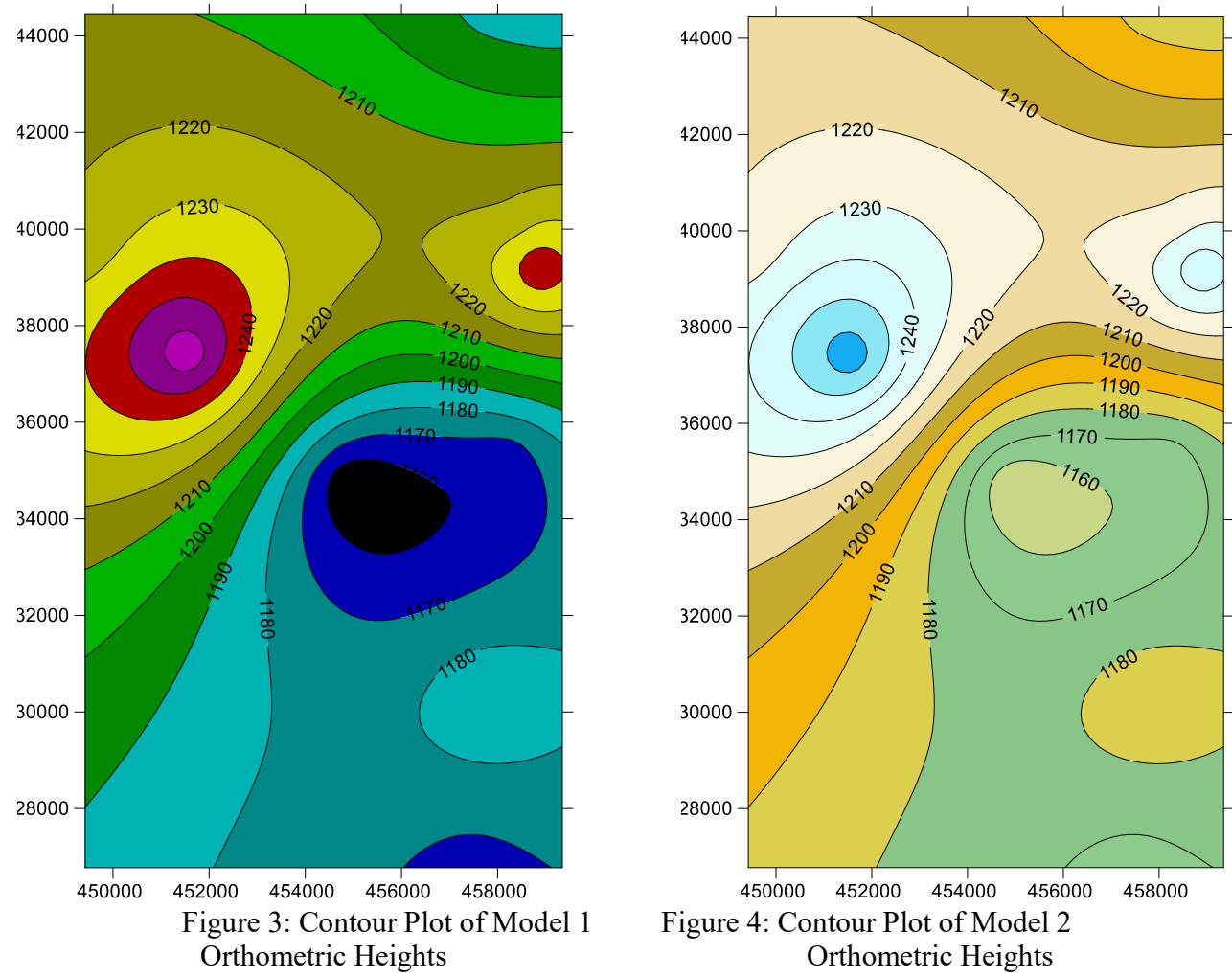

Figure 4: Contour Plot of Model 2

Orthometric Heights

Orthometric Heights

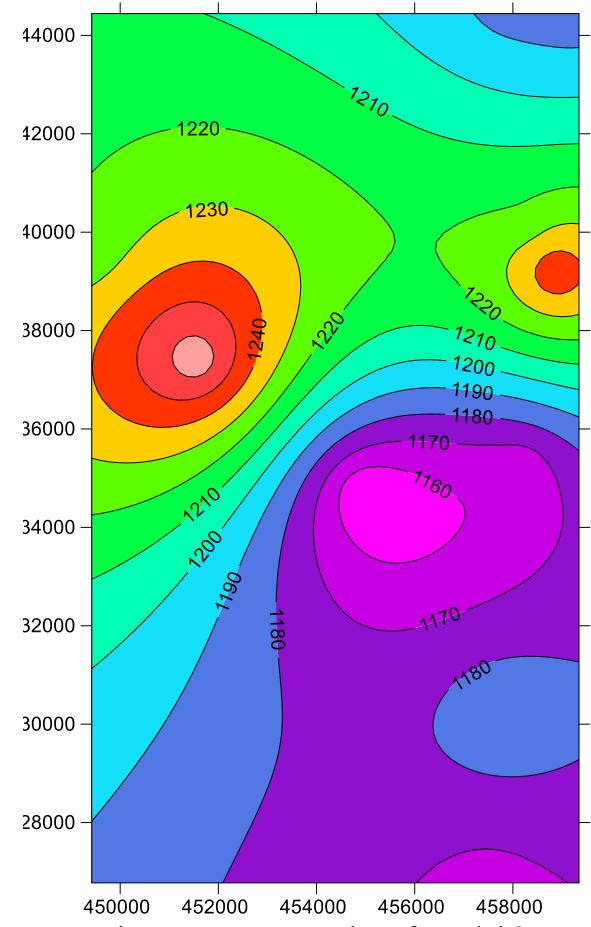

Figure 5: Contour Plot of Model 3 Orthometric Heights

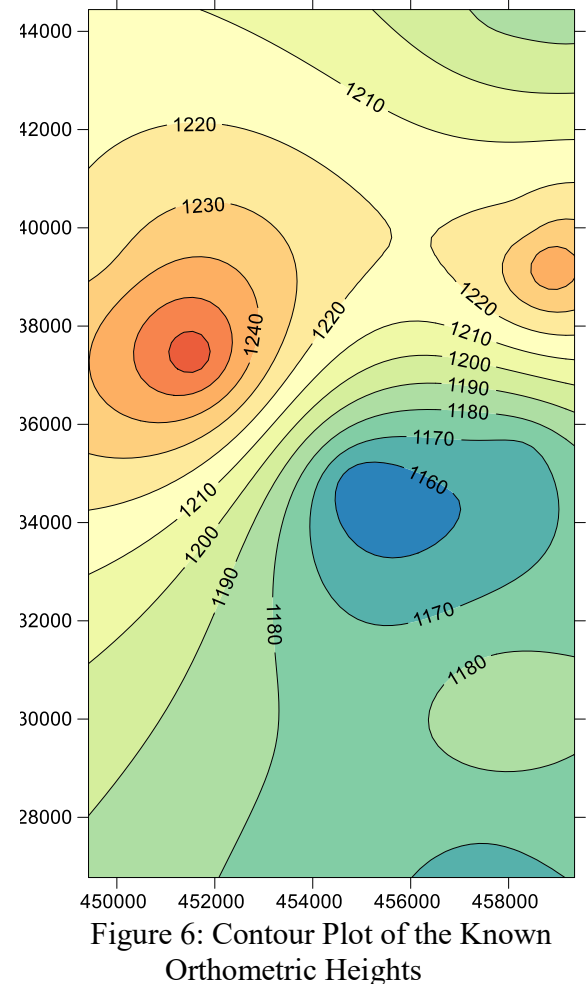

Table 4 presents the computed RMSEs of the three geometric geoid models of the study area. The RMSEs of the three geoid models were computed with the 12 points used for the determination of the models to compare the accuracy of the three geoid models to determine which of them is most suitable for application in the study area. The accuracy of the model is inversely 
proportional to the computed value of the RMSE. Therefore, the smaller the computed RMSE value, the higher the accuracy. It can be seen in Table 4 that the RMSEs of Models 1, 2 and 3 are respective $0.048 \mathrm{~m}, 0.044 \mathrm{~m}$ and $0.047 \mathrm{~m}$. It implies that Model 2 is most suitable for application in the study area.

Table 4: Models 1, 2 and 3 RMSEs

\begin{tabular}{cccc}
\hline & \multicolumn{3}{c}{ RMSE } \\
\hline Station & $\begin{array}{c}\text { Dff. b/w Known H } \\
\text { and Model 1 H } \\
\text { Squared (m) }\end{array}$ & $\begin{array}{c}\text { Dff. b/w Known H } \\
\text { and Model 2 H } \\
\text { Squared (m) }\end{array}$ & $\begin{array}{c}\text { Dff. b/w Known H } \\
\text { and Model 3 H } \\
\text { Squared (m) }\end{array}$ \\
\hline $\mathbf{7 1 Y 6 5}$ & 0.001190754 & 0.000020820 & 0.000193387 \\
$\mathbf{7 1 Y 8 0}$ & 0.000075383 & 0.000085953 & 0.000007216 \\
$\mathbf{7 1 Y 9 7}$ & 0.000529574 & 0.002002292 & 0.001296752 \\
$\mathbf{7 1 Y 1 2 5}$ & 0.016237504 & 0.008786065 & 0.013396262 \\
$\mathbf{7 1 Y 1 4 1}$ & 0.001130201 & 0.002005987 & 0.002407356 \\
$\mathbf{7 1 Y 1 4 3}$ & 0.005348817 & 0.005367070 & 0.005004249 \\
$\mathbf{7 1 Y 1 4 9}$ & 0.001136665 & 0.000232971 & 0.001699064 \\
$\mathbf{7 1 Y 1 5 1}$ & 0.000103819 & 0.000377920 & 0.000007582 \\
$\mathbf{7 1 Y 1 5 2}$ & 0.001263377 & 0.001916712 & 0.001668608 \\
$\mathbf{7 1 Y 1 5 3}$ & 0.000414214 & 0.000332562 & 0.000024855 \\
$\mathbf{7 1 Y 1 5 4}$ & 0.000148775 & 0.000002057 & 0.000128597 \\
$\mathbf{7 1 Y 1 5 5}$ & 0.000343770 & 0.001944201 & 0.000484578 \\
$\mathbf{R M S E}(\mathbf{m})=$ & $\mathbf{0 . 0 4 8 2 3 7 9 9 8}$ & $\mathbf{0 . 0 4 3 8 5 0 7 0 2}$ & $\mathbf{0 . 0 4 6 8 3 1 7 0 8}$ \\
\hline
\end{tabular}

Table 5 presents the computed RMSEs of the three geoid models using the three levelling points (stations 71Y121, 71Y126 and $71 \mathrm{Y} 147$ ). It was also done to determine which of the three models is most suitable in terms of accuracy for application in the study area. It can also be seen in Table 5 that the RMSEs of Models 1,2 , and 3 are respectively $0.091 \mathrm{~m}, 0.066 \mathrm{~m}$ and $0.089 \mathrm{~m}$. It as well shows that Model 2 is most suitable for application in the study area.

Table 5: Models 1, 2 and 3 RMSEs Using the Three Points Spirit Levelling Orthometric Heights

\begin{tabular}{cccc}
\hline \multicolumn{4}{c}{ Test Points by Spirit Levelling } \\
\hline Station & $\begin{array}{c}\text { Dff. b/w Spirit Levelling H } \\
\text { and Model 1 H Squared } \\
(\mathbf{m})\end{array}$ & $\begin{array}{c}\text { Dff. b/w Spirit Levelling } \\
\text { H and Model 2 H } \\
\text { Squared (m) }\end{array}$ & $\begin{array}{c}\text { Dff. b/w Spirit Levelling } \\
\text { H and Model 3 H } \\
\text { Squared (m) }\end{array}$ \\
\hline $\mathbf{7 1 Y 1 2 1}$ & 0.010292824 & 0.005761370 & 0.012577696 \\
$\mathbf{7 1 Y 1 2 6}$ & 0.006365151 & 0.005570688 & 0.004126757 \\
$\mathbf{7 1 Y 1 4 7}$ & 0.008245191 & 0.001609436 & 0.007279882 \\
RMSE $(\mathbf{m})=$ & $\mathbf{0 . 0 9 1 1 1 0 1 2 7}$ & $\mathbf{0 . 0 6 5 6 7 9 7 6 4}$ & $\mathbf{0 . 0 8 9 4 1 3 5 2 6}$ \\
\hline
\end{tabular}

Table 6 presents the computed RMSEs of the three geoid models using the four points (U2004 to U2007) whose orthometric heights were obtained by gravimetric means. It was as well done to determine which of the three models is most suitable in terms of accuracy for application in the study area. It can also be seen in Table 6 that the RMSEs of Models 1, 2, and 3 are respectively $0.182 \mathrm{~m}, 0.239 \mathrm{~m}$ and $0.200 \mathrm{~m}$ which shows that Model 1 with RMSE of $0.182 \mathrm{~m}$ is most suitable for application in the study area.

Table 6: Models 1, 2 and 3 RMSEs Using the Four Points Gravimetric Orthometric Heights

$$
\text { Test Points by Gravimetric Geoid (EIGEN 6C4) }
$$

\begin{tabular}{cccc}
\hline Station & $\begin{array}{c}\text { Dff. b/w Gravimetric H } \\
\text { and Model 1 H Squared } \\
(\mathbf{m})\end{array}$ & $\begin{array}{c}\text { Dff. b/w Gravimetric H } \\
\text { and Model 2 H } \\
\text { Squared (m) }\end{array}$ & $\begin{array}{c}\text { Dff. b/w Gravimetric H } \\
\text { and Model 3 H Squared } \\
(\mathbf{m})\end{array}$ \\
\hline $\mathbf{U 2 0 0 7}$ & 0.019749066 & 0.021835601 & 0.022338538 \\
$\mathbf{U 2 0 0 6}$ & 0.036861977 & 0.037627664 & 0.042998403 \\
$\mathbf{U 2 0 0 4}$ & 0.007899031 & 0.158347164 & 0.008743013 \\
$\mathbf{U 2 0 0 5}$ & 0.067964632 & 0.010797529 & 0.085729513 \\
RMSE $(\mathbf{m})=$ & $\mathbf{0 . 1 8 1 9 8 5 3 7 5}$ & $\mathbf{0 . 2 3 9 0 6 4 8 2 3}$ & $\mathbf{0 . 1 9 9 8 8 0 8 8 2}$ \\
\hline
\end{tabular}


The results, as well as the RMSEs $(0.048 \mathrm{~m}, 0.044 \mathrm{~m}$ and $0.047 \mathrm{~m}$ ) of the three models presented in Table 4 simply show that Model 2 is most suitable among the three models. But as the RMSEs of the three models differ with only about $4 \mathrm{~mm}$, the three models can be applied in the study area with more weight attached to model 2 . Also, considering that the results presented in Table 5 show that model 2 is most suitable for application in the study area, the three models can as well be applied in the study area for orthometric heights computation as their RMSE, as well as accuracy, differ by only about $2.5 \mathrm{~cm}$. Although, the accuracy of the three models presented in Table 6 are not as high as those respectively presented in Table 4 and Table 5 when the 12 points used for the geoid modelling and the 3 levelling points orthometric heights, were used. Also, the results presented in Table 6 show that model 1 is the best among the three models. It is well known that geoid modelling is carried out to replace spirit levelling whose fieldwork is tedious and time-consuming (Eteje et al., 2018). So, as the results of the spirit levelling validation, as well as the test points, agree with those of the 12 points used for the geoid modelling, the three models can be applied in the study area with more reliability, as well as confidence in model 2. Also, the accuracy achieved for the three geoid models agrees with those obtained by Oduyebo et al. (2019) for Benin City and Oluyori et al. (2018) for FCT, Abuja all in Nigeria. The two studies applied the same method (geometric method) in small areas as well.

\section{CONCLUSION}

The study has determined the local geometric geoid model of Kampala by comparing the accuracy of three plane geometric geoid surfaces. The results of the study show that model 2 is the best for orthometric heights interpolation in the study area. The study has also developed Microsoft Excel programs for the application of the models in the study area. The determined model is useful to the Ministry of Land, Housing and Urban Development (MLHUD), Civil engineers, Surveyors and Geophysicists to convert ellipsoidal heights from GNSS observation to orthometric heights in the study area.

\section{REFERENCES}

Abdallah, A. K. (2010). Height Determination Using GPS Data, Local Geoid and Global Geopotential Models. Universiti Teknologi, Malaysia Institutional Repository, EPrints3.

Eteje, S. O. and Oduyebo, O. F. (2018). Local Geometric Geoid Models Parameters and Accuracy Determination Using Least Squares Technique. International Journal of Innovative Research and Development, 7(7): 251-257. DOI: http://doi.org/10.24940/ijird/2018/v7/i7/JUL18098.

Eteje, S. O., Oduyebo, O. F. and Olulade, S. A. (2018). Procedure for the Determination of Local Gravimetric Geometric Geoid Model. International Journal of Advances in Scientific Research and Engineering (IJASRE), 4(8): 206-214. DOI: http://doi.org/10.31695/IJASRE.2018.32858.

Heiskanen, W. A. and Moritz, H. (1967). Physical Geodesy. W. H. Freeman, San Francisco, 364pp.

Irumba, R. (2015). Modelling of Construction Safety Performance and Housing Markets in Kampala City, Uganda.
Published Doctoral Thesis, Building and Real Estate Economics, Department of Real Estate and Construction Management KTH Royal Institute of Technology, Stockholm.

Kostelecký, J., Klokocník, J., Bucha, B., Bezdek, A. and Förste, C. (2015). Evaluation of the Gravity Field Model EIGEN-6C4 in Comparison with EGM2008 by Means of Various Functions of the Gravity Potential and by GNSS/Levelling. Geoinformatics FCE CTU, 14(1): 7-28. DOI: http://doi.org/10.14311/gi.14.1.1.

MLHUD (2019). Uganda Geodetic Reference Frame. Ministry of Land, Housing and Urban Development.

Oduyebo, O. F., Ono, M. N. and Eteje, S. O. (2019). Comparison of Three Gravimetric-Geometric Geoid Models for Best Local Geoid Model of Benin City, Nigeria. International Journal of Advanced Engineering Research and Science (IJAERS), 6(12): 261-272. DOI: https://dx.doi.org/10.22161/ijaers.612.23.

Oluyori, P. D. (2019). Modelling of Orthometric Heights from Multi-Networks of GNSS/Precise Levelling in Federal Capital Territory, Abuja, Nigeria, Unpublished PhD Dissertation, Department of Surveying and Geoinformatics, Nnamdi Azikwe University, Awka, Anambra State Nigeria.

Oluyori, P. D., Ono, M. N. and Eteje, S. O. (2018). Comparison of Two Polynomial Geoid Models of GNSS/Levelling Geoid Development for Orthometric Heights in FCT, Abuja. International Journal of Engineering Research and Advanced Technology (IJERAT), 4(10): 1-9. DOI: http://doi.org/10.31695/IJERAT.2018.3330.

Oluyori, P. D., Ono, M. N. and Eteje, S. O. (2018). Computations of Geoid Undulation from Comparison of GNSS/Levelling with EGM2008 for Geodetic Applications. International Journal of Scientific and Research Publications (IJSRP), $\quad$ 8(10): 235-241. http://dx.doi.org/10.29322/IJSRP.8.10.2018.p8230

Oonyu, J. and Esaete, J. (2012). "Kampala City”, Stimulus Paper PASCAL International Exchanges. College of Education and External Studies, Makerere University, Uganda.

Romans, D. (2007). Datum, Height and Geodesy. Central Chapter of the Professional Land Surveyors of Colorado 2007 Annual Meetings.

Schofield, W. (2007). Engineering Surveying: Theory and Examination Problems for Students, $5^{\text {th }}$ Edition Kingston University.

Shako, R., Förste, C., Abrikosov, O., Bruinsma, S., Marty, J., Lemoine, J., ... Dahle, C. (2013). A High-Resolution Global Gravity Combination Model Including GOCE Data. Advanced Technologies in Earth Sciences. Springer, Berlin, Heidelberg, 155-161. DOI: https://dx.doi.org/10.1007/978-3-642-32135120 .

Ssengendo, R., Sjoberg L. E., Gidudu, A., (2015a). The Uganda Gravimetric Geoid Model 2014 computed by the KTH Method, 
Journal of Geodetic Science, 5:35-46.

Ubajekwe, R. (2011). Geometric Geodesy. Unpublished Lecture Note of the Department of Surveying and Geoinformatics, Nnamdi Azikiwe University, Awka. 